\title{
INFLUENCE OF GERMINATION TEMPERATURE AND TIME ON PHENOLIC CONTENT AND ANTIOXIDANT PROPERTIES OF CEREALS
}

\author{
Zanda Kruma $^{1 *}$, Tatjana Kince ${ }^{1}$, Ruta Galoburda ${ }^{1}$, Lolita Tomsone ${ }^{1}$, Evita Straumite ${ }^{1}$, Martins Sabovics ${ }^{1}$, \\ Ievina Sturite ${ }^{2}$, Arta Kronberga ${ }^{3}$ \\ I* Department of Food Technology, Faculty of Food Technology, Latvia University of Life Sciences and Technologies, Rigas iela 22, \\ Jelgava, Latvia, e-mail: zanda.kruma@llu.lv \\ ${ }^{2}$ Norwegian Institute of Bioeconomy Research (NIBIO), Ås, Akershus, Norway \\ ${ }^{3}$ Institute of Agricultural Resources and Economics, Latvia University of Life Sciences and Technologies, Zinatnes iela 2, \\ Priekuli, Latvia
}

\begin{abstract}
Germination improves nutritional quality of cereals due to synthesis of various phytochemicals. The aim of the current research was to evaluate influence of the applied germination conditions on the changes in total phenolic compounds (TPC) and antioxidant activity of triticale, hull-less barley, hull-less oat, wheat, and rye grains. Triticale (cv. Inarta), hull-less barley (cv. Irbe), hull-less oat (cv. Lizete), rye (cv. Kaupo), and wheat (cv. Ellvis) grains were cleaned, washed and steeped in water at the ratio of 1:2 (grains to water) for $24 \mathrm{~h}$ at $22 \pm 2{ }^{\circ} \mathrm{C}$. After steeping, grain germination was performed for $12,24,36$ and $48 \mathrm{~h}$ in the dark at $17{ }^{\circ} \mathrm{C}, 25^{\circ} \mathrm{C}, 35^{\circ} \mathrm{C}$ and the total phenolic content and antioxidant activity have been analysed by DPPH and ABTS assays. During germination, TPC in all analysed cereal types increased, but dynamics was cereal type dependent and it is not possible to give general tendency or the best parameters applicable for cereals in general. Most significant changes were observed in the analysed grains during germination at $25^{\circ} \mathrm{C}$ and $35^{\circ} \mathrm{C}$, with the highest increase in hull-less barley. The current study indicates that germination is effective tool for improvement of different grain nutritional value, suggesting their potential use in new product development.
\end{abstract}

Keywords: triticale, hull-less barley, hull-less oats, DPPH, ABTS

\section{Introduction}

Cereals are a very important part of human diet worldwide. Consumers prefer cereal-based products with improved functionality, and it can be reached by modifying technological processes (Henry et al., 2015). Selection of valuable, untraditional raw materials and technological processes resulting in increased nutritional quality are important factors in new product development. Triticale (Triticosecale Wittmack) is a promising substitute to wheat (Triticum spp.) in functional processed flour products such as bread, pasta etc. Triticale contains higher amounts of protein, ash and non-starch content of lipids, starch, lignin and bioactive compounds as polyphenols (Fraś et al., 2016). Applications of barley (Hordeum vulgare L.) in industrial processing has been widely evaluated, especially for possible use in food and feed due to its nutritional value. Hull-less barley has technological benefits due to the lack of hull, but also it differs in chemical composition resulting in higher content of insoluble and soluble fractions of dietary fibre and other bioactive compounds (Blandino et al., 2015; Kruma et al., 2016a). Oats (Avena sativa L.) also are divided in two groups - hulled and hull-less. The main application of hull-less oats in the world are for feed purposes. However, nutritional value of hull-less oats are characterised by higher content of proteins, lipids, fibres (Sterna et al., 2016) and similar content of phenolic compounds (Kruma et al., 2016a) compared to hulled samples. Rye grains are source of starch, dietary fibre and protein in the diet. Additionally, Pihlava et al. (2018) indicated that whole rye grain is a valuable source of diverse groups of phenolic compounds. Wheat is considered as a good source of energy and irreplaceable nutrients. However white flour has a low antioxidant capacity (Dziki et al., 2014).
Antioxidant activity of cereals is provided by phenolic compounds, as a major group of radical scavengers. These molecules are secondary metabolites of plants, which possess antioxidant activity and reduce damages caused by free radicals for human DNA, RNA etc. Recent investigations are focused on evaluating commonly consumed foods including cereals for their antioxidant properties. Several techniques are developed to reduce losses of phenolic compounds in foods and technologies are developed to increase their level (Wu et al., 2013). Germination process could increase their content resulting in food with improved nutritional value (Cevallos-Casals, Cisneros-Zevallos, 2010).

Germination is a competitive and economical approach to increase the nutritive quality and amount of bioactive compounds in cereal grains (Singh et al., 2015). Steeping is the first step in germination process with the aim to accelerate water penetration, which transforms the inactive tissue into living tissue, and grains metabolism is activated. Germination activates endogenous cereal enzymes, when proteins and carbohydrates are hydrolysed into smaller molecules as mono-, disaccharides, dextrin's, peptides, free amino acids, and additionally new bioactive compounds are synthetized (Wu et al., 2013). At the initial germination stages phenolics may serve as radical scavengers or antioxidants, while later they could become part of the structure for new growing plant and lose some of their antioxidant efficiency (Cevallos-Casals, CisnerosZevallos, 2010).

The aim of the current research was to evaluate influence of the applied germination conditions on the changes in total phenolic compounds (TPC) and antioxidant activity of triticale, hull-less barley, hull-less oat, wheat, and rye grains. 


\section{Materials and Methods \\ Plant material}

Triticale cv. Inarta, hull-less barley cv Irbe, hull-less oat cv. Stendes Emilija, rye cv. Kaupo, and wheat cv. Elvis grains were cultivated conventionally at the Institute of Agricultural Resources and Economics in 2015. The germination experiments were carried out at the laboratories of the Faculty of Food Technology at Latvia University Life Sciences and Technologies.

Grain germination

Cereals included in experiment were cleaned, washed and steeped in water at the ratio of 1:2 (grains to water) for $24 \pm 1 \mathrm{~h}$ at $22 \pm 2{ }^{\circ} \mathrm{C}$. After steeping, water was drained and grains were allowed to germinate for 12, 24, 36 and 48 hours in the dark at controlled temperature $(17,25$ and $35 \pm 2{ }^{\circ} \mathrm{C}$ with relative humidity (RH) $95 \pm 2 \%$. The climatic chamber ICH110 (Memmert, Germany) was used for germination process.

Extraction and determination of total phenolic compounds and antioxidant activity

Extraction procedure was applied as described by Kruma et al. (2016b). The total phenolic content (TPC) of the germinated cereal extracts was analysed in accordance with Folin-Ciocalteu spectrophotometric methodology (Singleton et al., 1999). Stable 2,2diphenyl-1-picrylhydraziyl (DPPH) radical and 2,2'azino-bis (3-ethylbenz-thiazoline-6-sulfonic) acid $\left(\mathrm{ABTS}^{+}\right)$radical cation assay was used to evaluate antioxidant activity. All analytical methods outlined in details by Kruma et al. (2016b).

\section{Statistical analysis}

The obtained data were analysed by analysis of variance (ANOVA); significance was defined at $\mathrm{p}<0.05$. Relationship between TPC and antioxidant activity such as $\mathrm{DPPH}^{-}$and $\mathrm{ABTS}^{+}$scavenging activity was estimated by a linear correlation analysis. The averages of triplicate extractions are reported.

\section{Results and Discussion}

\section{Total phenolic compounds (TPC)}

Comparing TPC between tested grains, hull-less barley showed the highest content and it is in agreement with the previous study (Kruma et al., 2016a). Also other authors emphasize benefits of barley, showing their antioxidant, antiradical, and antiproliferative effects. Incorporation of barley into the daily diet provide health benefits (Madhujith et al., 2007). During steeping process, TPC increased significantly (Fig. 2) and the highest increase was observed in hull-less barley sample (63\%).

The results indicate that physical modifications and enzymatic activity during steeping process increase phenolic content. Cereals contain both free and bound phenolic compounds and they are soluble-extractable polyphenols and insoluble-non-extractable (Arranz, Saura Calixto, 2010; Koletta et al., 2014). In the current experiment, extractable phenolic compounds were determined and increase could be explained by the increase in the fraction of soluble phenolic compounds due to hydrolysis of lignin and hemicelluloses bound forms from cell walls (Thammapat et al., 2015). Steeping was performed at $22{ }^{\circ} \mathrm{C}$ temperature, but in further experiments higher temperatures for hull less cereals and triticale were tested, because for rice the highest TPC has achieved by steeping at $50{ }^{\circ} \mathrm{C}$ (Thammapat et al., 2015).

During germination TPC in all analysed cereal types increased (Fig. 1-5) but the dynamics were cereal type dependent and it is not possible to give general tendency or the best germination parameters applicable for all cereals. As shown by Cevallos-Casals and CisnerosZevallos, (2010), phenolic compounds posing antioxidant activity are synthesised during germination which can result in germinated cereals with improved nutraceutical properties. Generally, germination at $17{ }^{\circ} \mathrm{C}$ temperature resulted in lower TPC. For triticale, no significant differences of TPC between germination at $25{ }^{\circ} \mathrm{C}$ and $35{ }^{\circ} \mathrm{C}$ were observed and the highest TPC after $24 \mathrm{~h}$ was reached. For hull-less oats the highest results were for samples germinated at $35{ }^{\circ} \mathrm{C}$, only at the end of the experiment (after 48 hours) no differences between $25^{\circ} \mathrm{C}$ and $35^{\circ} \mathrm{C}$ were observed. For hull-less barley the highest TPC was obtained after germination at $35^{\circ} \mathrm{C}$ for 24 hours. The same content is possible to reach also after 36 hours at $25^{\circ} \mathrm{C}$ and $35^{\circ} \mathrm{C}$ temperature. For wheat and rye, the highest results were for samples germinated at $25^{\circ} \mathrm{C}$ after 48 hours. Similar results about significant influence of germination time and temperature was obtained by several authors. Investigation of kiwicha sprouts indicated that germination temperature had more significant effect on the increase of phenolic content than time and their interaction (Paucar-Menacho et al., 2017), for brown rice the highest TPC was found in samples germinated at $28{ }^{\circ} \mathrm{C}$ for $96 \mathrm{~h}$ (Cáceres et al., 2014). In triticale the initial TPC was the lowest but during germination, it increased 2.5-fold, while for oats the results were even higher - a 2.6-fold increase was observed. However, hull-less barley which had the highest initial TPC out of all tested cereals, the increase during germination was the lowest (0.7-fold). Results can be associated with different controlling mechanism of enzymatic activity of hydrolases and polyphenol oxidases during germination (Mamilla, Mishra, 2017). Similar explanation was found also for brown rice showing activation of phenylpropanoid pathway and also hydrolyses of phenolic compounds incorporated into cell walls (He et al., 2011). Also, one of the explanations for the increase of TPC is a liberation of phenolic acids during germination process by enzymes that hydrolyses starch (Tian et al., 2010).

Comparing to raw materials in all germinated samples an increase of TPC was detected. Chen et al. (2016) investigated canary seeds germination and stated that the highest content of total phenolics was in germinated seeds followed by raw seeds and soaked seeds. Another study also confirmed this conclusion by testing different seeds and accumulated phenolics and antioxidant 
activity was the highest in 7-day sprouts and lowest in steeped seeds (Cevallos-Casals, CisnerosZevallos, 2010).

In literature a contrary trend with TPC decrease during germination has also been reported for purple corn and that can be explained by the activation of polyphenol oxidases that are involved in degradation of phenolic compounds in food matrixes (Paucar-Menacho et al., 2017). Germination conditions influenced TPC of the tested samples differently and it can be explained by physiological structure and chemical composition of cereals, but even together with temperature effect of cultivar was observed resulting in different TPC content (Cáceres et al., 2014). Temperature $26^{\circ} \mathrm{C}$ and time $63 \mathrm{~h}$ were identified as the optimal conditions by Response Surface Methodology for enhancing the $\gamma$-aminobutyric acid and TPC content as well as the antioxidant activity of purple corn (Paucar-Menacho et al., 2017).

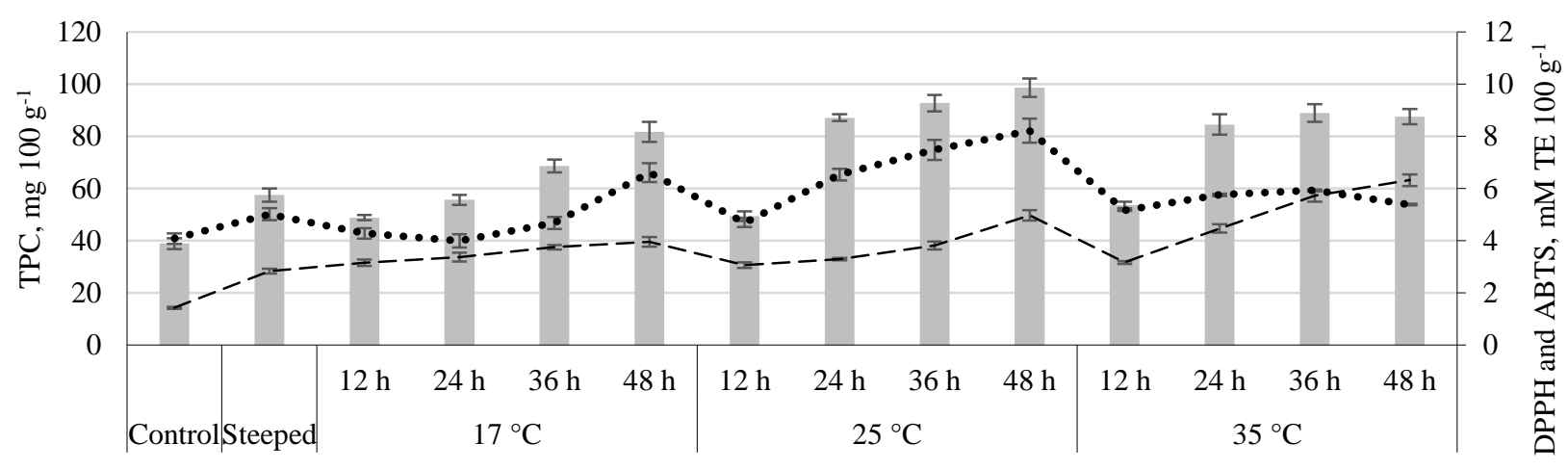

Germination temperature

ТPC ----DPPH $\cdots \cdot$... ABTS

Figure 1. Dynamics of TPC, DPPH, and ABTS during germination process in triticale

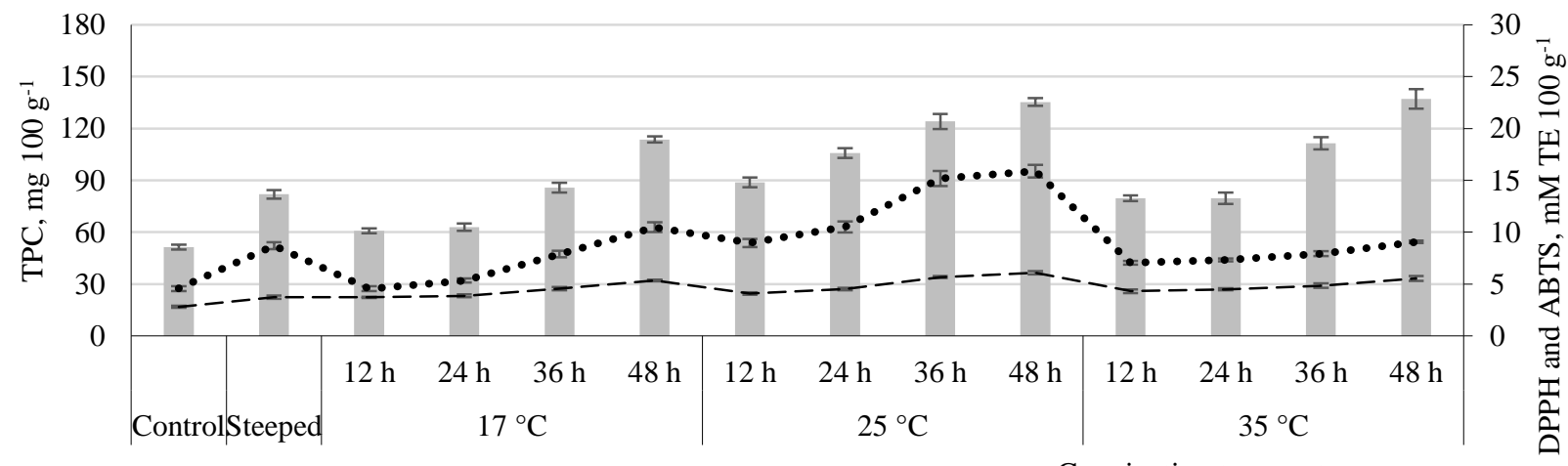

Germination temperature

TPC ----DPPH $\cdots . . \cdot$ ABTS

Figure 2. Dynamics of TPC, DPPH, and ABTS during germination process in hull-less oats

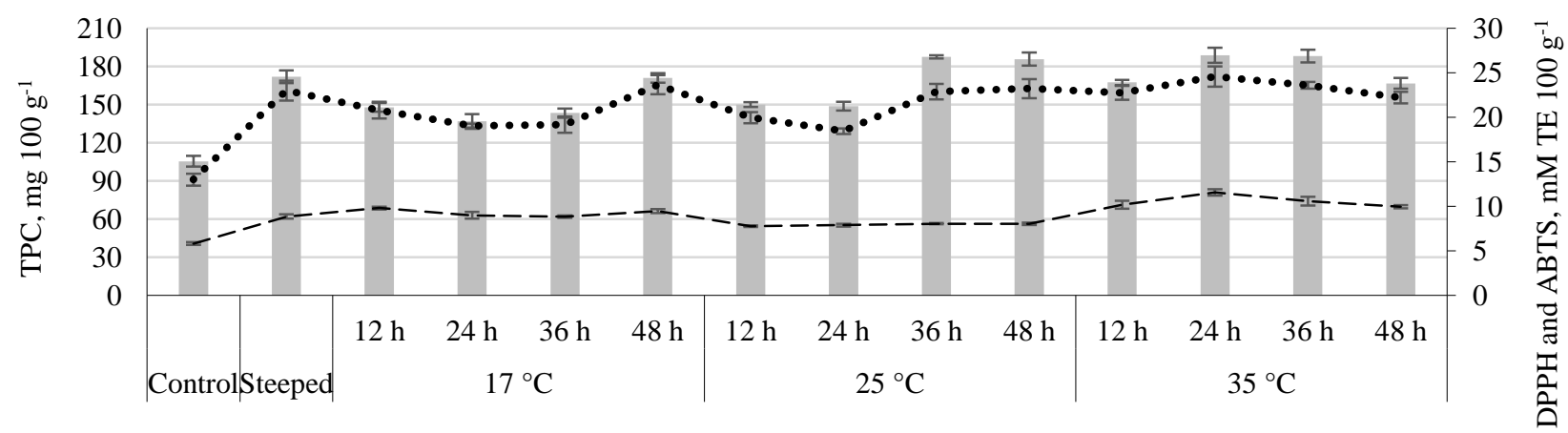

Germination temperature

TPC - DPPH

ABTS

Figure 3. Dynamics of TPC, DPPH, and ABTS during germination process in hull-less barley 


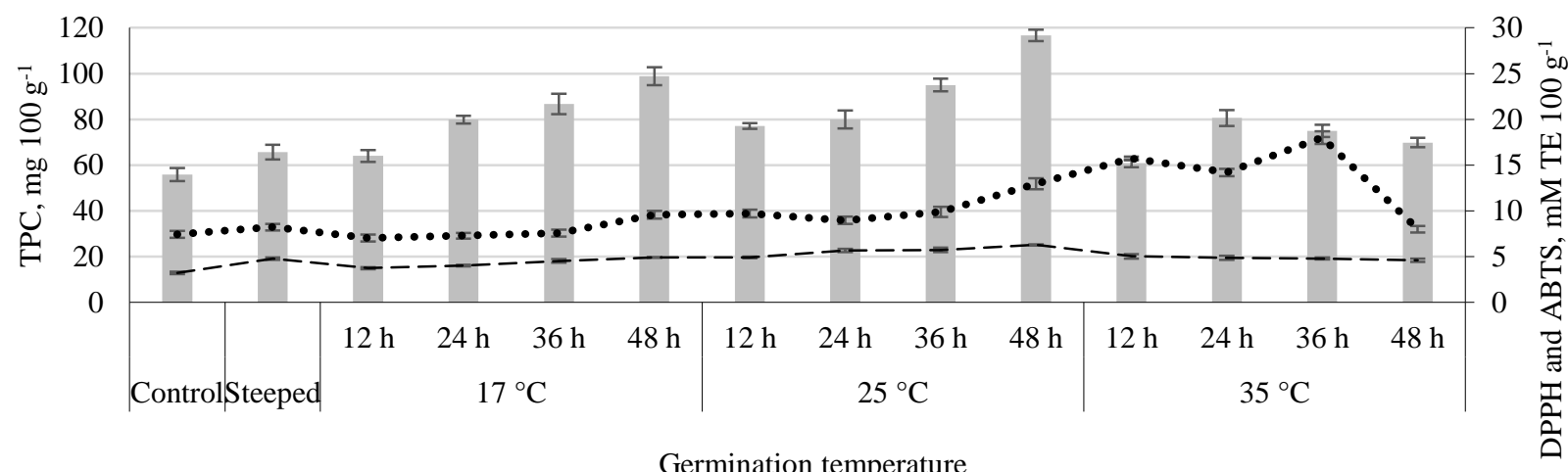

Germination temperature

TPC ----DPPH $\cdots \cdot . \cdot$ ABTS

Figure 4. Dynamics of TPC, DPPH, and ABTS during germination process in rye

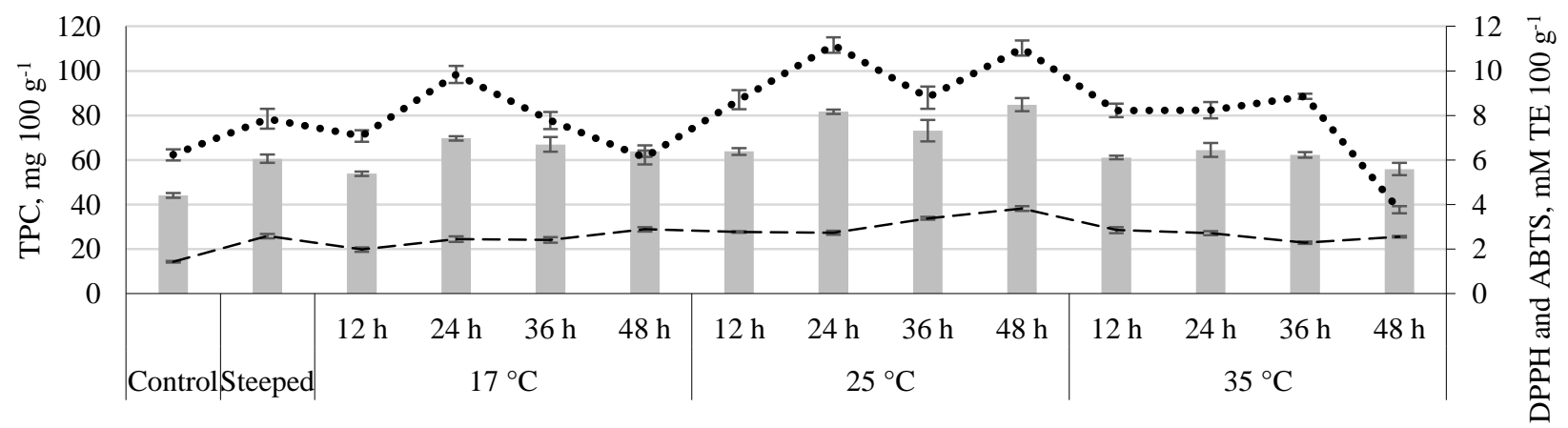

Germination temperature

TPC - - - DPPH $\cdots$-.... ABTS

Figure 5. Dynamics of TPC, DPPH, and ABTS during germination process in wheat

\section{Radical scavenging activity}

Assays of DPPH and $\mathrm{ABTS}^{+}$scavenging activity are widely used for evaluation the antioxidant activity of plant matrixes. Different antioxidant assays give different results due to radicals' activity (Aguilera et al., 2015). During steeping process, antioxidant activity increased significantly (Figures 1-5). The highest increase in ABTS scavenging activity was observed in steeped hull-less barley sample - by $77 \%$. Whereas the highest increase of DPPH activity was in triticale, reaching 97\%, although initial TPC and antioxidant activity in triticale was the lowest comparing all tested grains. Among the tested cereals steeped hull-less barley had the highest DPPH scavenging activity.

Also, Žilić et al. (2011) detected the higher DPPH radical scavenging activity in hull-less barley, which is in line with our study. DPPH activity during germination is time and temperature dependent. For triticale the highest increase was observed at $35^{\circ} \mathrm{C}$ temperature and reached the maximal activity after 48 hours. Whereas for wheat, rye and hull-less oats the highest results were reached after germination for 48 hours at $25^{\circ} \mathrm{C}$. Both time and temperature affected antioxidant activity positively but response of temperature was more intense (Paucar-Menacho et al., 2017). Whereas antioxidant activity results of other experiment showed up to 4-fold higher activity after $96 \mathrm{~h}$ germination of brown rice, and activity was cultivar specific (Cáceres et al., 2014).

For scavenging of ABTS cations temperature is significant factor. ABTS radical is widely applied for antioxidant assays due to its reactivity with different classes of antioxidants. But comparing to DPPH, its stability is lower and also preparation process is more time and chemicals consuming (Mareček et al., 2017). In triticale the best results were obtained during germination at $25^{\circ} \mathrm{C}$, and by increasing germination time, activity also increased. Also, for hull-less oats $25^{\circ} \mathrm{C}$ showed the best results, and the highest activity after 36 hours was reached. For hull-less barley the highest results after 24 hours were reached and the same tendency that was observed for TPC and DPPH scavenging activity. Results showed that ABTS determination more emphasised the effect of the variety on the total antioxidant capacity whereas DPPH scavenging activity showed the effect of the harvest year (Mareček et al., 2017).

Differences in antioxidant activity could also be explained by the results from experiments about $\beta$-glucan as antioxidant. Hull-less barley and oat cultivars compared to the hulled cultivars contains higher level of $\beta$-glucans, resulting in better nutritional value (Tiwari, Cummins, 2012). Antioxidant activity pathway of $\beta$-glucans is not well understood and 
$\beta$-glucan extracted from germinated barley showed higher antioxidant capacity comparing to ungerminated sample (Ronda et al., 2015). Also antioxidant activity can be affected by protein content and according to Mareček et al. (2017) higher protein content results in lower antioxidant activity

To understand the role of phenolic compounds in the radical scavenging activity of cereals, correlation analyses were performed. In Table 1 the Pearson's coefficients between the levels of phenolic compounds and antioxidant activity in tested cereal types are presented.

Table 1

The correlations between TPC and radical scavenging activity in germinated cereals

\begin{tabular}{lccc}
\hline \multicolumn{1}{c}{ Cereal } & $\begin{array}{c}\text { TPC / } \\
\text { DPPH }\end{array}$ & $\begin{array}{c}\text { TPC / } \\
\text { ABTS }\end{array}$ & $\begin{array}{c}\text { DPPH / } \\
\text { ABTS }\end{array}$ \\
\hline Triticale & 0.77 & 0.86 & 0.47 \\
Hull-less barley & 0.21 & 0.57 & 0.75 \\
Hull-less oats & 0.93 & 0.83 & 0.83 \\
Wheat & 0.81 & 0.79 & 0.46 \\
Rye & 0.71 & 0.13 & 0.42 \\
\hline
\end{tabular}

Triticale, hull-less oats, wheat and rye showed a highly positive correlation between the content of phenolic compounds and antioxidant activity. Lower values were obtained for hull-less barley. In cereals weak or moderate correlation between DPPH scavenging activity and TPC are observed because one of the main cereal phenolic acid - ferulic acid has weak antioxidant properties (Đorđević et al., 2010). It could be also explained by the contribution of other compounds to antioxidant activity. These compounds could be $\beta$-glucan, proteins etc.

Strong correlation between phenolic compounds and antioxidant capacity that was found in investigations of different cereals (Chen et al., 2016; Deng et al., 2012) showing that the phenolic compounds provide antioxidant activity of water-soluble fraction.

\section{Conclusions}

Germination process increased total phenol content and antiradical activity of cereal grains, and the most significant changes were observed in the analysed grains during germination at $25^{\circ} \mathrm{C}$ and $35^{\circ} \mathrm{C}$. Hull-less barley grains exhibited the highest changes in chemical composition among all tested cereals. During germination TPC in all analysed cereal types increased, but the dynamics were cereal type dependent, therefore, it is not possible to give general tendency and the best parameters applicable for all cereals. As phenolic compounds posing antioxidant activity are synthesised during germination, it can result in germinated cereals with improved nutraceutical properties, thus, suggesting potential use in new product development.

\section{Acknowledgment}

The research leading to these results has received funding from the Norwegian Financial Mechanism 2009-2014 under Project Innovative approach to hull- less spring cereals and triticale use from human health perspective (NFI/R/2014/011).

\section{References}

1. Aguilera Y., Herrera T., Benítez V., Arribas S. M., López de Pablo A. L., Esteban R. M., Martín-Cabrejas M. A. (2015) Estimation of scavenging capacity of melatonin and other antioxidants: Contribution and evaluation in germinated seeds. Food Chemistry, Vol. 170, p. 203-211.

2. Arranz S., Saura Calixto F. (2010) Analysis of polyphenols in cereals may be improved performing acidic hydrolysis: A study in wheat flour and wheat bran and cereals of the diet. Journal of Cereal Science, Vol. 51(3), p. 313-318.

3. Blandino M., Locatelli M., Gazzola A., Coïsson J. D., Giacosa S., Travaglia F., Bordiga M., Reyneri A., Rolle L. Arlorio M. (2015) Hull-less barley pearling fractions: Nutritional properties and their effect on the functional and technological quality in bread-making. Journal of Cereal Science, Vol. 65, p. 48-56.

4. Cáceres P.J., Martínez-Villaluenga C., Amigo L., Frias J. (2014) Maximising the phytochemical content and antioxidant activity of Ecuadorian brown rice sprouts through optimal germination conditions. Food Chemistry, Vol. 152, p. 407-414.

5. Cevallos-Casals B. A., Cisneros-Zevallos L. (2010) Impact of germination on phenolic content and antioxidant activity of 13 edible seed species. Food Chemistry, Vol. 119(4), p. 1485-1490.

6. Chen Z., Yu L., Wang X., Gu Z., Beta T. (2016) Changes of phenolic profiles and antioxidant activity in canaryseed (Phalaris canariensis L.) during germination. Food Chemistry, Vol. 194, p. 608-618.

7. Deng G.-F., Xu X.-R., Guo Y.-J., Xia E.-Q., Li S., Wu S., Chen F., Ling W.H., Li H.-B. (2012) Determination of antioxidant property and their lipophilic and hydrophilic phenolic contents in cereal grains. Journal of Functional Foods, Vol. 4(4), p. 906-914.

8. Đorđević T. M., Šiler-Marinković S. S., DimitrijevićBranković S. I. (2010) Effect of fermentation on antioxidant properties of some cereals and pseudo cereals. Food Chemistry, Vol 119(3), p. 957-963.

9. Dziki D., Rózyło R., Gawlik-Dziki U., Świeca M. (2014) Current trends in the enhancement of antioxidant activity of wheat bread by the addition of plant materials rich in phenolic compounds. Trends in Food Science and Technology, Vol. 40(1), p. 48-61.

10. Fraś A., Gołębiewska K., Gołębiewski D., Mańkowski D. R., Boros D., Szecówka P. (2016) Variability in the chemical composition of triticale grain, flour and bread. Journal of Cereal Science, Vol. 71, p. 66-72.

11. He D., Han C., Yao J., Shen S., Yang P. (2011) Constructing the metabolic and regulatory pathways in germinating rice seeds through proteomic approach. Proteomics, Vol. 11, p. 2693-2713.

12. Henry R. J., Rangan P., Furtado A. (2015) Developing cereals acceptable to consumers for production in new and variable climates. Procedia Environmental Sciences, Vol. 29, p. 9-10.

13. Koletta P., Irakli M., Papageorgiou M., Skendi A. (2014) Physicochemical and technological properties of highly enriched wheat breads with wholegrain non wheat flours. Journal of Cereal Science, Vol. 60(3), p. 561-568.

14. Kruma Z., Tomsone L., Galoburda R., Straumite E., Kronberga A., Åssveen M. (2016a) Total phenols and 
antioxidant capacity of hull-less barley and hull-less oats. Agronomy Research, Vol. 14(Special Iss. 2), p. 1361-1371.

15. Kruma Z., Tomsone L., Ķince T., Galoburda R., Senhofa S., Sabovics M., Straumite E., Sturite I. (2016b) Effects of germination on total phenolic compounds and radical scavenging activity in hull-less spring cereals and triticale. Agronomy Research, Vol. 14(2), p. 1372-1383.

16. Madhujith T., Shahidi F. (2007) Antioxidative and antiproliferative properties of selected barley (Hordeum vulgarae L.) cultivars and their potential for inhibition of low-density lipoprotein (LDL) cholesterol oxidation. Journal of Agricultural and Food Chemistry, Vol. 55(13), p. 5018-5024.

17. Mamilla R. K., Mishra V. K. (2017) Effect of germination on antioxidant and ACE inhibitory activities of legumes. LWT - Food Science and Technology, Vol. 75, p. 51-58.

18. Mareček V., Mikyška A., Hampel D., Čejka P., Neuwirthová J., Malachová A., Cerkal R. (2017) ABTS and DPPH methods as a tool for studying antioxidant capacity of spring barley and malt. Journal of Cereal Science, Vol. 73, p. 40-45.

19. Paucar-Menacho L. M., Peñas E., Dueñas M., Frias J., Martínez-Villaluenga C. (2017) Optimizing germination conditions to enhance the accumulation of bioactive compounds and the antioxidant activity of kiwicha (Amaranthus caudatus) using response surface methodology. LWT-Food Science and Technology, Vol. 76, p. 245-252.

20. Pihlava J. M., Hellström J., Kurtelius T., Mattila P. (2018) Flavonoids, anthocyanins, phenolamides, benzoxazinoids, lignans and alkylresorcinols in rye (Secale cereale) and some rye products. Journal of Cereal Science, Vol. 79, p. $183-192$.

21. Ronda F., Perez-Quirce S., Lazaridou A., Biliaderis C.G. (2015) Effect of barley and oat $\beta$-glucan concentrates on gluten-free rice-based doughs and bread characteristics. Food Hydrocolloids, Vol. 48, p. 197-207.

22. Singh A.K., Rehal J., Kaur A., Jyot G. (2015) Enhancement of attributes of cereals by germination and fermentation: A Review. Critical Reviews in Food Science and Nutrition, Vol. 55(11), p. 1575-1589.

23. Singleton V.L., Orthofer R., Lamuela-Raventos R.M. (1999) Analysis of total phenols and other oxidation substrates and antioxidants by means of Folin-Ciocalteu reagent. Methods in Enzymology, Vol. 119(25), p. $152-178$.

24. Sterna V., Zute S., Brunava L. (2016) Oat grain composition and its nutrition benefice. Agriculture and Agricultural Science Procedia, Vol. 8, p. 252-256.

25. Thammapat P., Meeso N., Siriamornpun S. (2015) Effects of $\mathrm{NaCl}$ and soaking temperature on the phenolic compounds, $\alpha$-tocopherol, $\gamma$-oryzanol and fatty acids of glutinous rice. Food Chemistry, Vol. 175, p. 218-224.

26. Tian B., Xie B., Shi J., Wu J., Cai Y., Xu T., Xue S.J., Deng Q. (2010) Physicochemical changes of oat seeds during germination. Food Chemistry, Vol. 119(3), p. 1195-1200.

27. Tiwari U., Cummins E. (2012) Dietary exposure assessment of $\beta$-glucan in a barley and oat-based bread. LWT-Food Science and Technology, Vol. 47(2), p. 413-420.

28. Wu F., Yang N., Touré A., Jin Z., Xu X. (2013) Germinated brown rice and its role in human health. Critical Reviews in Food Science and Nutrition, Vol. 53(5). p. 451-463.

29. Žilić S., Hadži-Tašković Šukalović V., Dodig D., Maksimović V., Maksimović M., Basić Z. (2011) Antioxidant activity of small grain cereals caused by phenolics and lipid soluble antioxidants. Journal of Cereal Science, Vol. 54(3), p. 417-424. 